OPEN ACCESS

Edited by:

Luc Pellerin,

University of Poitiers, France

Reviewed by:

Grant Robert Gordon,

University of Calgary, Canada

Angus M. Brown,

University of Nottingham,

United Kingdom

*Correspondence:

Nina Vardjan

nina.vardjan@mf.uni-lj.si

Specialty section:

This article was submitted to

Integrative Physiology,

a section of the journal

Frontiers in Physiology

Received: 02 July 2021 Accepted: 06 September 2021 Published: 30 September 2021

Citation:

Horvat $A$, Zorec $R$ and

Vardjan N (2021) Lactate as an

Astroglial Signal Augmenting Aerobic Glycolysis and Lipid Metabolism.

Front. Physiol. 12:735532.

doi: 10.3389/fphys.2021.735532

\section{Lactate as an Astroglial Signal Augmenting Aerobic Glycolysis and Lipid Metabolism}

\author{
Anemari Horvat ${ }^{1,2}$, Robert Zorec ${ }^{1,2}$ and Nina Vardjan ${ }^{1,2 *}$ \\ 'Laboratory of Neuroendocrinology - Molecular Cell Physiology, Institute of Pathophysiology, Faculty of Medicine, \\ University of Ljubljana, Ljubljana, Slovenia, ${ }^{2}$ Laboratory of Cell Engineering, Celica Biomedical, Ljubljana, Slovenia
}

Astrocytes, heterogeneous neuroglial cells, contribute to metabolic homeostasis in the brain by providing energy substrates to neurons. In contrast to predominantly oxidative neurons, astrocytes are considered primarily as glycolytic cells. They take up glucose from the circulation and in the process of aerobic glycolysis (despite the normal oxygen levels) produce $\mathrm{L}$-lactate, which is then released into the extracellular space via lactate transporters and possibly channels. Astroglial L-lactate can enter neurons, where it is used as a metabolic substrate, or exit the brain via the circulation. Recently, L-lactate has also been considered to be a signaling molecule in the brain, but the mechanisms of L-lactate signaling and how it contributes to the brain function remain to be fully elucidated. Here, we provide an overview of $\mathrm{L}$-lactate signaling mechanisms in the brain and present novel insights into the mechanisms of $\mathrm{L}$-lactate signaling via G-protein coupled receptors (GPCRs) with the focus on astrocytes. We discuss how increased extracellular L-lactate upregulates cAMP production in astrocytes, most likely via $\mathrm{L}$-lactate-sensitive $\mathrm{G}_{\mathrm{s}}$-protein coupled GPCRs. This activates aerobic glycolysis, enhancing L-lactate production and accumulation of lipid droplets, suggesting that L-lactate augments its own production in astrocytes (i.e., metabolic excitability) to provide more $\mathrm{L}$-lactate for neurons and that astrocytes in conditions of increased extracellular L-lactate switch to lipid metabolism.

Keywords: L-lactate, L-lactate sensitive receptors, astrocytes, CAMP, aerobic glycolysis, lipid metabolism

\section{INTRODUCTION}

Historically, L-lactate was first considered as a cellular waste product of glycolytic metabolism, however, it was later proposed that L-lactate can also act as a supplemental oxidative energy substrate and as a signaling molecule in the brain (Dienel, 2012a; Magistretti and Allaman, 2018).

$\mathrm{L}$-Lactate is involved in various cellular processes in the brain, including in the regulation of intracellular $\mathrm{Ca}^{2+}$ signaling (Requardt et al., 2012), cell energy metabolism (Bergersen and Gjedde, 2012; Barros, 2013), activity of various channels and transporters (Gordon et al., 2008; Ohbuchi et al., 2010), myelination (Fünfschilling et al., 2012), and gene expression (Yang et al., 2014; Descalzi et al., 2019). L-Lactate was shown to support high-level cognitive functions, learning and long-term memory formation (Newman et al., 2011; Suzuki et al., 2011; Gibbs, 2015; Murphy-Royal et al., 2020), and may have a neuroprotective role against excitotoxicity (Ros et al., 2001) and ischemia (Berthet et al., 2012; Castillo et al., 2015). Moreover, impaired 
L-lactate signaling and metabolism have been associated with several brain pathologies, such as epilepsy (Yang et al., 2016), depression (Carrard et al., 2018), and neurodevelopmental disorders [e.g., X-linked intellectual disability (XLID); D’Adamo et al., 2021]. However, the molecular mechanisms of the broad spectrum of L-lactate functions in the brain in health and disease are not yet clear (Dienel, 2012a) and may involve the role of L-lactate as an energy substrate and as a signaling molecule in the brain.

The brain is composed of various cell types with distinct metabolic profiles. Under physiologic conditions, astrocytes and mature oligodendrocytes are considered mainly glycolytic cells, whereas neurons and microglia are predominantly oxidative (Fünfschilling et al., 2012; Zhang et al., 2014; Sharma et al., 2015; Afridi et al., 2020; Yang et al., 2021). A high glycolytic rate with L-lactate production is present in astrocytes and oligodendrocytes during increased neuronal activity despite normal brain oxygen levels, a process termed aerobic glycolysis (Pellerin and Magistretti, 1994; Barros, 2013; Saab et al., 2016), also known as the Warburg effect initially described in fast proliferating cancer cells (Warburg, 1956; Vander Heiden et al., 2009). To avoid L-lactate-mediated intracellular acidification, which causes negative feedback on glycolytic flux (Hertz et al., 2014), L-lactate is shuttled intra-/intercellularly and extracellularly by diffusion down its concentration gradient via membrane monocarboxylate transporters (MCTs; PérezEscuredo et al., 2016), $\mathrm{K}^{+} /$voltage-sensitive cation channels (Sotelo-Hitschfeld et al., 2015), pannexin and connexin hemichannels (Karagiannis et al., 2016), and gap junctions (Scemes et al., 2017). Shuttling of brain L-lactate enables neurons to accept L-lactate and use it as an energy fuel in oxidative metabolism (Hertz et al., 2014). L-Lactate can also act as a signaling molecule intracellularly or extracellularly indirectly or via receptor-mediated signaling mechanisms (Barros, 2013; Mosienko et al., 2015). Due to its signaling characteristics and shuttling capability, L-lactate may act as a brain "volume transmitter", activating L-lactate-sensitive receptors (LLRs) on neural cells that are relatively distant from the site of L-lactate release. In this way, L-lactate-mediated signals could spread over larger areas of the brain (Bergersen and Gjedde, 2012).

In this review, we first discuss the current knowledge on intracellular and extracellular L-lactate signaling mechanisms in the brain with an emphasis on receptor-based signaling in astrocytes, where L-lactate is predominantly produced in the brain. Then, we discuss how extracellular L-lactate augments astroglial aerobic glycolysis and thus its own production and how this may contribute to L-lactate "volume transmission". The role of L-lactate as a metabolic substrate and signal in the control of brain lipid metabolism is also addressed.

\section{MOLECULAR MECHANISMS OF L-LACTATE SIGNALING IN THE BRAIN}

In the brain, L-lactate can exert its role as a signaling molecule through several intracellular and extracellular mechanisms.

\section{Intracellular L-Lactate Signaling in the Brain}

Once inside the cells, L-lactate can modulate brain function indirectly by changing the intracellular redox state of cells as glycolytic transformation of L-lactate into pyruvate generates $\mathrm{NADH}$ and thus increases the NADH/NAD ${ }^{+}$ratio (Hung et al., 2011; Hertz et al., 2014). By altering the cellular redox state, L-lactate (1) promotes the expression of synaptic plasticityrelated genes, such as Arc, c-Fos, and Zif268, by potentiating ionotropic glutamate receptor (NMDA receptor)-mediated $\mathrm{Ca}^{2+}$ currents induced by glutamate and glycine leading to activation of a downstream Erk1/2 signaling cascade in neurons in vitro and in vivo (Yang et al., 2014) and (2) modulates astroglial $\mathrm{Ca}^{2+}$ signaling by increasing the frequency of dopamine-induced $\mathrm{Ca}^{2+}$ signals (Requardt et al., 2012). The entry of L-lactate into cells can also affect the cell energy status where L-lactate is first metabolized to pyruvate, which is then used for generation of ATP in the tricarboxylic acid cycle (TCA) leading to an increased ATP/ADP ratio. This was shown to regulate the activity of ATP-sensitive $\mathrm{K}^{+}$channels in hypothalamic and orexin neurons, which close when cytoplasmic ATP levels increase, leading to depolarization of the membrane (Song and Routh, 2005; Parsons and Hirasawa, 2010; Mosienko et al., 2015). Lastly, L-lactate uptake via MCTs is accompanied by the cotransport of protons, causing intracellular acidification (Nedergaard and Goldman, 1993), which can modulate brain energy metabolism by inhibiting phosphofructokinase (PFK), a glycolytic enzyme extremely sensitive to small changes in pH (Dienel, 2012b), and potentially other nearby ion channels, transporters, and receptors.

\section{Extracellular L-Lactate Signaling in the Brain}

Some actions of L-lactate cannot be attributed to its intracellular signaling activity, but can only be explained by L-lactate acting extracellularly as a signaling molecule. Increases in extracellular L-lactate levels that occur in the brain in response to (1) increased brain activity, (2) low oxygen availability, both triggering glycolysis and L-lactate release from neural cells, and/or (3) increased blood L-lactate levels (Boumezbeur et al., 2010; Mosienko et al., 2015) were linked to various cellular responses in the brain. Increased extracellular L-lactate due to low oxygen levels in the brain hinders prostaglandin $\mathrm{E}_{2}\left(\mathrm{PGE}_{2}\right)$ clearance, a known vasodilator, from the extracellular space by affecting prostaglandin transporter efficacy. Consequently, PGE2 concentration in the extracellular space increases, resulting in vasodilation (Gordon et al., 2008). Moreover, in rat hypothalamic vasopressin neurons, extracellular L-lactate was shown to potentiate the activity of acid-sensing ion channels (ASICs), voltage-insensitive cationic channels activated by extracellular acidification. In these neurons, L-lactate $(15 \mathrm{mM})$, through chelation of extracellular $\mathrm{Ca}^{2+}$, which competes with $\mathrm{H}^{+}$at the activation site of ASICs, increases the sensitivity of ASICs to $\mathrm{H}^{+}$leading to enhanced acid-induced currents (Ohbuchi et al., 2010). Various recent studies suggest that extracellular L-lactate can also activate LLRS on neural cells (Table 1), causing 
activation of glucose and lipid metabolism in primary cortical astrocytes, modulation of neuronal activity of primary cortical neurons, and release of noradrenaline from noradrenergic neurons (Bozzo et al., 2013; Lauritzen et al., 2014; Tang et al., 2014; Mosienko et al., 2018; Vardjan et al., 2018; D’Adamo et al., 2021).

$\mathrm{L}$-Lactate is a weak agonist of the $\mathrm{G}_{\mathrm{i} / \mathrm{o}}$-protein coupled hydroxycarboxylic acid receptor 1 (HCAR1 or HCA1; $\mathrm{EC}_{50}$ of 1-5 mM; Liu et al., 2009), formerly known as orphan G-protein coupled receptor 81 (GPR81). GPR81 was first discovered in adipose tissue (Cai et al., 2008; Liu et al., 2009) and later researched in various cancers and cancer cell lines (Baltazar et al., 2020) and skeletal muscle (Rooney and Trayhurn, 2011). Although the expression level of GPR81 in the brain cells appears to be negligible according to the RNA sequencing databases and proteomic analysis (Zhang et al., 2014; Sharma et al., 2015; Zhang et al., 2016), GPR81 has been detected in the brain tissue by anti-GPR81 antibodies (Lauritzen et al., 2014). According to this study, cerebral GPR81 is concentrated predominantly in the postsynaptic membranes of the excitatory neuronal synapses, but can also be found, although to a much lesser extent, at the perisynaptic astroglial processes and at the blood-brain barrier, in particular in endothelial cells and perivascular astrocytic processes (Lauritzen et al., 2014). Consistent with the studies using anti-GPR81 antibodies, quantitative RT-PCR experiments confirmed the expression of GPR81 in mouse brain, including the cerebellum, hippocampus, and cerebral cortex (Lauritzen et al., 2014), and in isolated rat and mouse cortical astrocytes (Vardjan et al., 2018). Although under physiologic conditions, extracellular concentrations of L-lactate, that are fluctuating between the sub- and low millimolar range $(0.1-1.4 \mathrm{mM})$ in rodent brain and around $5 \mathrm{mM}$ in human brain, as measured by microdialysis in different brain areas (Abi-Saab et al., 2002; Mosienko et al., 2015), might be too low to fully activate GPR81, brain extracellular L-lactate concentrations can increase to several millimolar (Mosienko et al., 2015) under certain (patho)physiologic conditions, which could activate GPR81. For instance, (1) during exercise, when L-lactate blood levels increase and L-lactate enters the brain from the systemic circulation (usually the L-lactate concentration in the brain is lower than in the circulation; Bergersen, 2015), as GPR81-mediated effects of exercise on brain function were demonstrated in mice that have been subjected to high-intensity interval exercise or L-lactate injection mimicking exercise-induced increase in blood L-lactate levels (Morland et al., 2017); (2)

TABLE 1 | Astroglial and neuronal L-lactate-sensitive receptors and their effects on intracellular signaling and metabolism.

\begin{tabular}{|c|c|c|c|c|c|c|c|c|}
\hline \multirow{2}{*}{ Receptor } & \multirow{2}{*}{$\begin{array}{l}\text { G-protein } \\
\text { coupling }\end{array}$} & \multirow{2}{*}{$\begin{array}{l}\text { L-Lactate } \\
\text { sensitivity }\end{array}$} & \multicolumn{2}{|c|}{ Intracellular signaling } & \multicolumn{2}{|c|}{ Metabolic effects } & \multirow{2}{*}{ Other agonists } & \multirow{2}{*}{ References } \\
\hline & & & Astrocytes & Neurons & Astrocytes & Neurons & & \\
\hline GPR81 (HCAR1) & $\mathrm{G}_{\mathrm{i}}$ & $\sim 4-30 \mathrm{mM}$ & n.d. & $\begin{array}{l}\downarrow \mathrm{Ca}^{2+} \text {-transient } \\
\text { frequency }\end{array}$ & n.d. & n.d. & $\begin{array}{l}\text { 3,5-DHBA } \\
\alpha \text {-HBA } \\
\text { Glycolate } \\
\gamma \text {-HBA } \\
3 \mathrm{Cl}-5 \mathrm{OH}-\mathrm{BA} \\
\text { Compound } 2\end{array}$ & $\begin{array}{l}\text { Liu et al., 2009, 2012; } \\
\text { Dvorak et al., 2012; Bozzo } \\
\text { et al., 2013; Lauritzen et al., } \\
\text { 2014; Sakurai et al., } 2014\end{array}$ \\
\hline Neuronal LLRx & $\mathrm{G}_{\mathrm{s}}$ & $0.5 \mathrm{mM}$ & n.d. & $\begin{array}{l}\uparrow[\mathrm{CAMP}]_{\mathrm{i}} \\
\uparrow \mathrm{PKA} \text { activity }\end{array}$ & n.d. & n.d. & $\begin{array}{l}\text { D-Lactate } \\
\text { (antagonist) } \\
\text { MPA } \\
\text { aHIBA } \\
\text { HMBA } \\
2 \text { HPA } \\
\text { KA }\end{array}$ & $\begin{array}{l}\text { Tang et al., 2014; Mosienko } \\
\text { et al., } 2018\end{array}$ \\
\hline $\begin{array}{l}\text { Astroglial } \\
\text { unidentified LLR }\end{array}$ & $\mathrm{G}_{\mathrm{s}}$ & $20 \mathrm{mM}$ & $\begin{array}{l}\uparrow[\mathrm{CAMP}]_{\mathrm{i}} \\
\uparrow \mathrm{PKA} \text { activity }\end{array}$ & n.d. & $\begin{array}{l}\downarrow\left[\text { glucose }_{i}\right. \\
\uparrow[\text { lactate }]_{i} \\
\uparrow \text { lipid droplet } \\
\text { accumulation }\end{array}$ & n.d. & $\begin{array}{l}3 \mathrm{Cl}-5 \mathrm{OH}-\mathrm{BA} \\
\text { Compound } 2\end{array}$ & $\begin{array}{l}\text { Vardjan et al., 2018; } \\
\text { D'Adamo et al., 2021; } \\
\text { Smolič et al., } 2021\end{array}$ \\
\hline Olfr78* (OR51E2) & $\mathrm{G}_{\mathrm{s}}$ & $\sim 4 \mathrm{mM}$ & / & n.d. & / & n.d. & $\begin{array}{l}\text { Acetate } \\
\text { Propionate }\end{array}$ & $\begin{array}{l}\text { Conzelmann et al., 2000; } \\
\text { Chang et al., 2015; } \\
\text { Mosienko et al., } 2018\end{array}$ \\
\hline GPR4 & $\begin{array}{l}\text { Presumable } \\
\text { allosteric } \\
\text { modulation }\end{array}$ & $1-10 \mathrm{mM}$ & n.d. & n.d. & n.d. & n.d. & $\mathrm{H}^{+}$ & Hosford et al., 2018 \\
\hline
\end{tabular}

GPR81, G-protein coupled receptor 81; HCAR1, hydroxycarboxylic acid receptor 1; LLR, L-lactate-sensitive receptor; Olfr78, L-lactate-sensitive olfactory receptor 78; OR51E2, human orthologue of L-lactate-sensitive olfactory receptor 78; GPR4, proton-sensitive G-protein coupled receptor 4; 3,5-DHBA, 3,5-dihydroxybenzoic acid; $\alpha$-HBA, $\alpha$-hydroxybutyrate; $\gamma$-HBA, $\gamma$-hydroxybutyrate; 3Cl-5OH-BA, 3-chloro-5-hydroxybenzoic acid; Compound 2, 2,4-methyl-N-(5-(2-(4-methylpiperazin-1-yl)-2-oxoethyl)-4-(2-thienyl)-1,3thiazol-2-yl) cyclohexanecarboxamide; MPA, (S)-(-)-2-methoxypropionic acid; aHIBA, $\alpha$-hydroxyisobutyric acid; HMBA, 2-hydroxy-3-methyl-butyric acid; 2HPA, (S)-2-hydroxypentanoic acid; KA, kynurenic acid; PKA, protein kinase A; [CAMP], intracellular concentration of cAMP; [glucose]; intracellular concentration of free D-glucose; [lactate], intracellular concentration of L-lactate; and n.d., not determined.

${ }^{*}$ Not expressed in astrocytes. 
when oxygen or glucose supplies in the brain are low (e.g., during hypoxia, ischemia, seizures, and hyperglycemia; Smith et al., 1986; During et al., 1994; Lee et al., 2015; Mosienko et al., 2015); and (3) when the gene expression profile of neural cells is changed favoring L-lactate production/accumulation (Afridi et al., 2020). Moreover, one can speculate that under physiologic conditions in response to increased neuronal activity, L-lactate is released from neural cells locally, in microdomains. In microdomains, the L-lactate concentration is likely high enough to fully activate GPR 81 , however, the presence of such microdomains in the brain needs to be determined in the future (Morland et al., 2015; Mosienko et al., 2015).

Activation of the GPR81 in adipose tissue through $\mathrm{G}_{\mathrm{i} / \mathrm{o}^{-}}$ proteins downregulates the formation of cAMP. This leads to the inhibition of lipolysis, promoting lipid storage in adipocytes (Ahmed et al., 2010). Similar to adipocytes, GPR81 activation in cancer and muscle cells decreases cAMP levels (Sun et al., 2016; Feng et al., 2017), which is crucial for cancer cell survival (Roland et al., 2014) and maintenance of mitochondrial function (Sun et al., 2016; Baltazar et al., 2020), respectively. Consistent with these results, in rat hippocampal slices, increase in forskolin-induced cAMP was inhibited by L-lactate at concentrations $>10 \mathrm{mM}$ and by selective GPR81 receptor agonist 3,5-dihydroxybenzoic acid (3,5-DHBA) with half maximal inhibitory concentration $\left(\mathrm{IC}_{50}\right)$ of $1.4 \mathrm{mM}$, as measured by cAMP radioimmunoassay on homogenized brain slices (Lauritzen et al., 2014). Moreover, L-lactate (in a concentration-dependent manner with $\mathrm{IC}_{50}$ of $\sim 4.2 \mathrm{mM}$ ) and selective GPR81 agonist 3,5-DHBA (1 mM) decreased the spontaneous electrical activity of isolated mouse cortical neurons measured as a decrease in $\mathrm{Ca}^{2+}$-transient frequency. This most likely occurs via $\mathrm{G}_{\mathrm{i}}$-protein activation given that pertussis toxin, an inhibitor of $\mathrm{G}_{\mathrm{i}}$-proteins, prevented the decrease of neuronal activity by L-lactate (Bozzo et al., 2013), suggesting that brain GPR81 is also coupled to $\mathrm{G}_{\mathrm{i} / \mathrm{o}}$-proteins and responds only to supraphysiologic L-lactate concentrations (Lauritzen et al., 2014).

Recently, it has been proposed that noradrenergic neurons (Tang et al., 2014; Mosienko et al., 2018) and cortical astrocytes (Vardjan et al., 2018; D’Adamo et al., 2021) may respond to extracellular L-lactate through as yet unidentified LLRs that are coupled to $\mathrm{G}_{\mathrm{s}}$-proteins and cAMP production, which is discussed in more detail in the following section.

\section{RECEPTOR-MEDIATED L-LACTATE SIGNALING IN ASTROCYTES}

Astrocytes, although electrically silent cells, can respond to many, if not all, signaling molecules in the brain (e.g., glutamate, ATP, noradrenaline, GABA, acetylcholine, serotonin, dopamine, cannabinoid, and bradykinin) through metabotropic G-protein coupled receptors (GPCRs) expressed on their surface. Activation of astroglial GPCRs can change intracellular $\mathrm{Ca}^{2+}$ and/or cAMP signals (i.e., cytoplasmic excitability) via receptor coupling to $\mathrm{G}_{\mathrm{q}^{-}}$and/or $\mathrm{G}_{\mathrm{s}^{-}}$and $\mathrm{G}_{\mathrm{i} / \mathrm{o}^{-}}$-proteins, respectively (Vardjan and Zorec, 2015), which affects astrocyte function and control of brain homeostasis (Verkhratsky and Nedergaard, 2018). Recently, extracellular $\mathrm{L}$-lactate was identified as a novel signaling molecule in the brain that could excite L-lactate-sensitive GPCRs. Initially, GPR81 receptor, coupled to $\mathrm{G}_{\mathrm{i} / \mathrm{o}}$-proteins and downregulation of cAMP production, was suggested to be involved in L-lactate signaling in astrocytes (Lauritzen et al., 2014), but recently, another as yet unidentified GPCR, most likely coupled to $\mathrm{G}_{\mathrm{s}}-$ proteins and upregulation of cAMP production, has been linked to L-lactate-mediated signaling in astrocytes (Vardjan et al., 2018; D’Adamo et al., 2021).

Intracellular $\mathrm{Ca}^{2+}$ and cAMP imaging of rat cortical astrocytes revealed that $\mathrm{Ca}^{2+}$ signals in astrocytes, preloaded with a $\mathrm{Ca}^{2+}$ indicator Fluo-4 AM (D'Adamo et al., 2021), are not affected by extracellular L-lactate $(20 \mathrm{mM})$ and a selective GPR81 agonist, 3-chloro-5-hydroxybenzoic acid (3Cl-5OH-BA; $0.5 \mathrm{mM}$; Vardjan et al., 2018; D'Adamo et al., 2021), while both agonists trigger a persistent increase in intracellular cAMP and protein kinase A (PKA) activity in astrocytes. The latter occurs within $~ 100 \mathrm{~s}$ (cAMP) and 200 s (PKA) upon stimulation, as measured by genetically encoded fluorescence resonance energy transfer (FRET)-based cAMP sensor Epac1-camps and a cAMP-dependent PKA activity sensor AKAR2 (Vardjan et al., 2018; D'Adamo et al., 2021). The L-lactate-induced increase in cAMP depends on the activity of transmembrane adenylate cyclase (AC; Figure 1), given that the treatment of cells with an AC inhibitor 2',5'-dideoxyadenosine (DDA; $100 \mu \mathrm{M})$ reduced the $20 \mathrm{mM}$ $\mathrm{L}$-lactate-induced increase in cAMP levels by $\sim 50 \%$, consistent with a $\mathrm{G}_{\mathrm{s}}$-protein signaling mechanism. Surprisingly, 3Cl-5OH-BA $(0.5 \mathrm{mM})$ and a high-affinity GPR81 agonist, 2,4-methyl-N-(5-(2-(4-methylpiperazin-1-yl)-2-oxoethyl)-4-(2thienyl)-1,3-thiazol-2-yl) cyclohexanecarboxamide (Compound 2; $50 \mathrm{nM}$; Sakurai et al., 2014) also trigger increases in cAMP in cortical astrocytes isolated from GPR81 knockout (KO) mice (Vardjan et al., 2018), indicating that L-lactate-triggered cAMP increases in astrocytes are independent of GPR81 receptor activation (Vardjan et al., 2018). These data obtained by realtime fluorescence microscopy contrast with the results obtained on adult rat hippocampal slices, where downregulation of cAMP production upon stimulation of tissue with extracellular L-lactate and selective GPR81 agonist 3,5-DHBA was linked to the activation of brain GPR81. In hippocampal slices, L-lactate and GPR81 agonist 3,5-DHBA exhibited concentration-dependent inhibition of forskolin-stimulated cAMP production with $\mathrm{IC}_{50}$ of $\sim 29 \mathrm{mM}$ and $1.4 \mathrm{mM}$, respectively. However, the brain cell type responsible for the observed downregulation of cAMP signals in hippocampal slices was not identified, as cAMP content was determined on homogenized tissue samples containing all brain cells (Lauritzen et al., 2014), suggesting that brain cells other than astrocytes, which express only low amounts of GPR81 (Lauritzen et al., 2014; Zhang et al., 2014; Sharma et al., 2015; Zhang et al., 2016), are responsible for L-lactate-mediated downregulation of cAMP generation in hippocampal slices.

Thus, astrocytes, in addition to GPR81, most likely express another, yet unidentified LLR coupled to $\mathrm{G}_{\mathrm{s}}$-proteins and AC-mediated cAMP production, which is also activated by GPR81 agonists and responds with increases in cAMP only 


\section{ASTROCYTE}

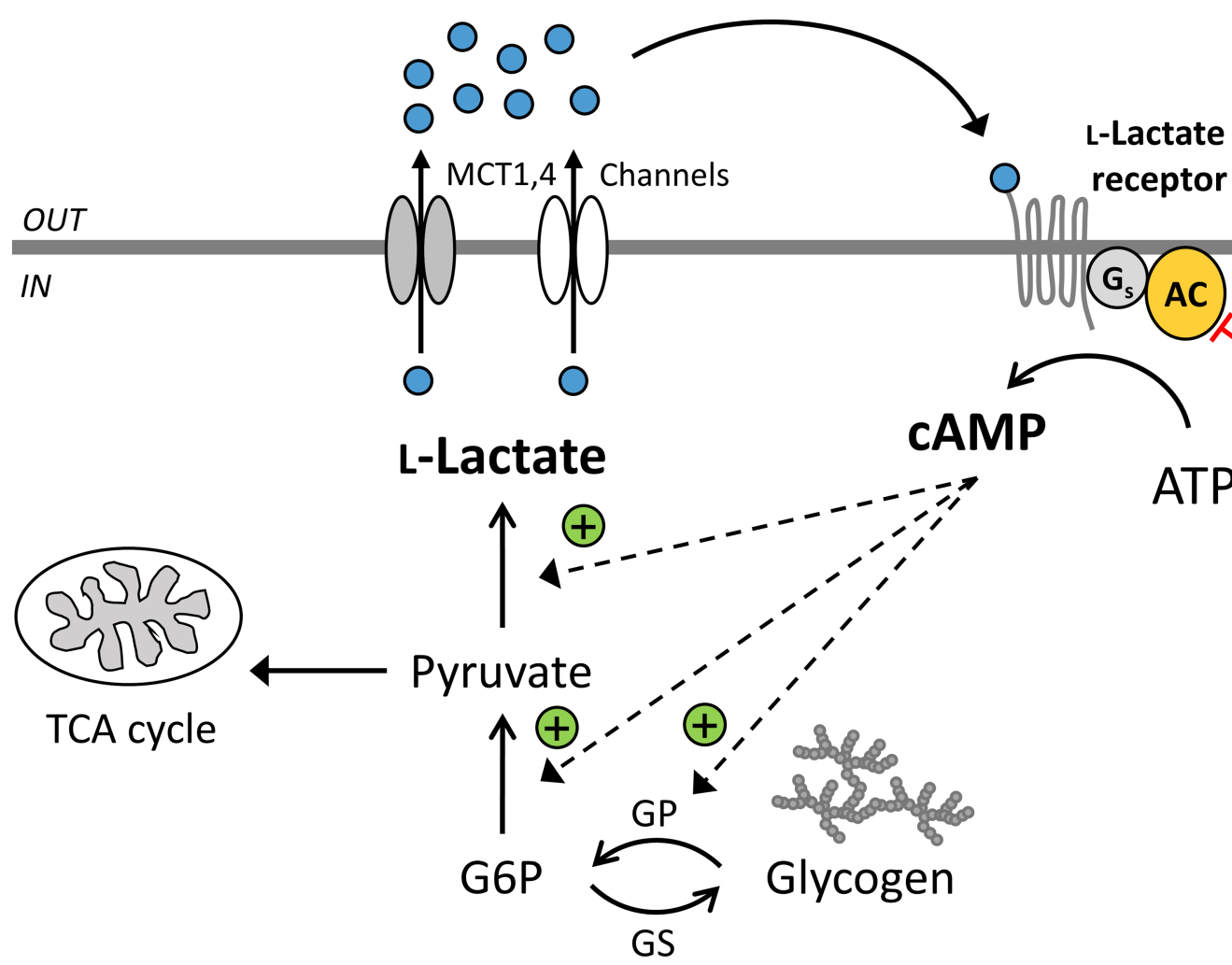

FIGURE 1 | Extracellular L-lactate enhances cytosolic L-lactate production via yet unidentified receptors coupled to adenylate cyclase (AC) activity and cAMP signaling in astrocytes. L-Lactate (blue circles) is formed in astrocytes $(\mathrm{IN})$ in the process of aerobic glycolysis and released through monocarboxylate transporters (MCTs) 1,4 and/or L-lactate-permeable channels. Extracellularly (OUT), L-lactate can be transported to neighboring cells as a fuel, it can exit the brain via the circulation, or act as a signaling molecule. By binding to the L-lactate-sensitive receptors (LLRs) on the surface of astrocytes, it can stimulate AC and cAMP production. This triggers glycogen degradation, glycolysis, and more L-lactate production. The inhibition of AC by 2 ',5'-dideoxyadenosine (DDA) causes a reduction in the astroglial LLR-mediated increase in cAMP and L-lactate levels (red line). L-Lactate-positive feedback mechanism ("metabolic excitability") in astrocytes may maintain the $\mathrm{L}$-lactate tissue concentration gradient between astrocytes and neighboring cells, enhancing the availability of $\mathrm{L}$-lactate as a metabolic fuel when brain energy demands are high. DDA, 2',5'-dideoxyadenosine, an inhibitor of AC; TCA cycle, tricarboxylic acid cycle; G6P, glucose 6-phosphate; GP, glycogen phosphorylase; and GS, glycogen synthase. Channels denote lactate-permeable $\mathrm{K}^{+} /$voltage-sensitive cation channels, pannexin and connexin hemichannels.

to supraphysiologic $(20 \mathrm{mM})$ extracellular L-lactate concentrations (Table 1), given that $2 \mathrm{mM}$ extracellular L-lactate concentration did not affect intracellular cAMP signals in astrocytes (Vardjan et al., 2018; D'Adamo et al., 2021). Interestingly, astroglial sensitivity to L-lactate-mediated cAMP elevation was increased in Gdil KO cortical astrocytes isolated from a mouse model of GDI1-associated XLID (D'Adamo et al., 2021), a form of neurodevelopmental disorder characterized by "pure" mental deficiency (Curie et al., 2009). GDI1 encodes for $\alpha$ GDI (Rab GDP dissociation inhibitor alpha) protein which regulates the GDP/GTP exchange reaction of most Rab proteins that are associated with vesicle traffic of molecules between cellular organelles (Stenmark, 2009). Namely, in Gdi1 KO astrocytes, but not Gdi1 WT astrocytes, extracellular L-lactate triggered intracellular cAMP increases already at a physiologic L-lactate concentration of $2 \mathrm{mM}$ (D'Adamo et al., 2021), possibly due to altered expression level of the astroglial LLR and/or downstream signaling factors, which may contribute to the metabolic imbalance and disease in this form of neurodevelopmental disorder (D'Adamo et al., 2021).

Consistent with the results obtained on rat and mouse isolated cortical astrocytes, the existence of a neuronal LLR that activates AC and cAMP production, named LLRx, was proposed in locus coeruleus (LC) noradrenergic neurons, which can, in contrast to an astroglial LLR, respond to physiologic extracellular L-lactate concentrations (Table 1; Tang et al., 2014; Mosienko et al., 2018). Studies performed on brainstem organotypic-cultured slices from rat pups containing LC noradrenergic neurons showed that exogenously applied L-lactate $(2 \mathrm{mM})$, as well as L-lactate released from astrocytes in response 
to optogenetic excitation, trigger depolarizations in noradrenergic neurons and subsequent release of stress response neuromodulator noradrenaline. The latter was suppressed if the slices were treated with oxamate $(20 \mathrm{mM})$, an L-lactate synthesis inhibitor, or 1,4-dideoxy-1,4-imino-d-arabinitol (DAB; $500 \mu \mathrm{M})$, a glycogen shunt activity inhibitor, implying that astroglial-derived L-lactate is involved in activation of noradrenergic neurons. Moreover, treatment of slices with AC inhibitor SQ22536 $(100 \mu \mathrm{M})$ and PKA inhibitor H89 $(10 \mu \mathrm{M})$ suppressed the depolarizing effect of $2 \mathrm{mM} \mathrm{L}$-lactate, indicating involvement of $\mathrm{G}_{\mathrm{s}}$-protein coupled receptors and the cAMP/PKA signaling pathway in L-lactatemediated activation of noradrenergic neurons. The authors also propose that noradrenaline released from noradrenergic neurons can then back-excite neighboring astrocytes (Tang et al., 2014; Mosienko et al., 2018), most likely via astroglial adrenergic receptors (Bekar et al., 2008; Hertz et al., 2010; O’Donnell et al., 2012; Ding et al., 2013; Vardjan et al., 2014; Horvat et al., 2016), which may affect astrocyte function, including glucose metabolism, which is highly regulated in the brain by the activity of noradrenergic neurons (Bélanger et al., 2011; O'Donnell et al., 2012; Gibbs, 2015; Dienel and Cruz, 2016; Vardjan and Zorec, 2017; Bak et al., 2018).

So far, two $G_{s}$-coupled LLRs were identified in the brain: olfactory receptor Olfr78 (human ortholog OR51E2) in mouse olfactory sensory neurons in certain brain areas (i.e., brainstem and nucleus tractus solitarius; Conzelmann et al., 2000) and GPR4 expressed in neurons in various rodent brain areas, such as retrotrapezoid and raphe nuclei, rostral ventrolateral medulla, septum, and LC (Table 1; Mosienko et al., 2017; Hosford et al., 2018; Mosienko et al., 2018). According to the RNA sequencing database (Zhang et al., 2014), Olfr78 and GPR4 expression in astrocytes is negligible, and most likely does not contribute to the observed L-lactate-induced increases in cAMP signals in astrocytes.

\section{EXTRACELLULAR L-LACTATE AND CONTROL OF ASTROGLIAL AEROBIC GLYCOLYSIS}

Astrocytes are key neural cells controlling metabolic homeostasis of the brain (Verkhratsky and Nedergaard, 2018). Due to their specific glycolytic profile, they are the main site of L-lactate production and release and an almost exclusive store of glycogen in the brain, which they can rapidly mobilize to enter the glycolytic pathway (Magistretti and Allaman, 2015; Oz et al., 2015; Bak et al., 2018).

As a response to increased neuronal activity, astrocytes upregulate glucose metabolism, i.e., glucose uptake from the circulation, glycogenolysis, and aerobic glycolysis with L-lactate production (Pellerin and Magistretti, 1994; Hertz et al., 2015; Dienel and Cruz, 2016). Astrocytes can sense neuronal activity via changes in extracellular $\mathrm{K}^{+}$(Bittner et al., 2011; SoteloHitschfeld et al., 2015), and glutamate levels (Pellerin and Magistretti, 1994), both tightly coupled with $\mathrm{Na}^{+}$fluxes across the membrane (Bittner et al., 2011; Chatton et al., 2016; Rose and Verkhratsky, 2016). Astrocytes respond to local increase in extracellular $\mathrm{K}^{+}$with plasma membrane depolarization leading to an increase in intracellular $\mathrm{pH}$, mediated by an electrogenic $\mathrm{Na}^{+} / \mathrm{HCO}_{3}{ }^{-}$cotransporter (NBCe1), which stimulates aerobic glycolysis (Ruminot et al., 2011), most likely through activation of PFK, a pH-sensitive glycolytic enzyme (Dienel, 2012b) and/ or $\mathrm{HCO}_{3}^{-}$-mediated activation of soluble AC (Choi et al., 2012). On the other hand, extracellular glutamate stimulates astroglial aerobic glycolysis to provide energy for the activity of the $\mathrm{Na}^{+} / \mathrm{K}^{+}$ATPase pump, which is activated by an increase in the intracellular concentration of $\mathrm{Na}^{+}$due to $\mathrm{Na}^{+}$-glutamate cotransport into astrocytes (Pellerin and Magistretti, 1994, 1996; Bittner et al., 2011). Active neurons also release $\mathrm{NH}_{4}{ }^{+}$, a by-product of catabolism, which in astrocytes causes an increase in intracellular $\mathrm{L}$-lactate concentration in vitro and in vivo. However, the effect of $\mathrm{NH}_{4}{ }^{+}$on L-lactate production is not due to glycolytic stimulation, instead it affects mitochondrial pyruvate shunting by diverting the flux of pyruvate from mitochondria to L-lactate production (Lerchundi et al., 2015). Moreover, astrocytes can also sense increased neuronal activity via signaling molecules released from activated neurons. The latter bind to astroglial metabotropic GPCRs and ionotropic receptors (Verkhratsky and Nedergaard, 2018), which leads to intracellular increases in $\mathrm{Ca}^{2+}$ and/or cAMP signals in astrocytes (Vardjan and Zorec, 2015). In astrocytes, both $\mathrm{Ca}^{2+}$ and cAMP can increase glycogenolysis and aerobic glycolysis with L-lactate production (Horvat et al., 2021). Astrocytes are also active participants in the neurovascular unit where they can respond to nitric oxide (NO) released by endothelial cells. NO inhibits astrocytic respiration and stimulates aerobic glycolysis, resulting in glucose depletion and L-lactate production via inhibition of mitochondrial cytochrome oxidase (Almeida et al., 2004; San Martín et al., 2017) and increased activity of 6-phosphofructo-1-kinase (PFK1), a master regulator of glycolysis (Almeida et al., 2004).

L-Lactate is not only produced but also released from astrocytes into the extracellular space via plasmalemmal lactate transporters MCT1 and 4, putative $\mathrm{K}^{+} /$voltage-sensitive cation channels (Sotelo-Hitschfeld et al., 2015), and/or hemichannels (Karagiannis et al., 2016). The presence of plasmalemmal L-lactate transporters in astrocytes and other brain cells represents the basis for a flux of L-lactate along its concentration gradient from astrocytes to (1) other brain cells, most importantly neurons (Pellerin and Magistretti, 1994, 2012) or (2) the circulation to exit the brain (Dienel, 2012a). According to the astrocyte-neuron L-lactate shuttle (ANLS) hypothesis, astroglial-derived extracellular L-lactate is taken up by neurons via the MCT2 transporters and fuels neuronal oxidative metabolism (Pellerin and Magistretti, 1994, 2012; Mächler et al., 2016), especially when energy demands are high, which is particularly important during memory formation and consolidation (Newman et al., 2011; Suzuki et al., 2011; Hertz et al., 2013; Descalzi et al., 2019; Murphy-Royal et al., 2020). Despite growing evidence supporting the ANLS hypothesis, the research community is not unanimous on this topic (Dienel, 2017, 2019). Some data challenge this hypothesis by showing that during brain activation neurons in acute mouse hippocampal brain slices and in vivo rely on their own L-lactate production rather than L-lactate derived from 
astrocytes to meet the increased energy demands, while ANLS may possibly function at rest, as studied by real-time two-photon fluorescence lifetime imaging microscopy (FLIM) of $\mathrm{NADH}$ dynamics (Díaz-García et al., 2017). One of the main arguments based on which the existence of an ANLS hypothesis has been questioned is that most of the past work supporting this process has been performed on primary astrocytes and neurons. However, recently ANLS was described by real-time two-photon FRET microscopy and L-lactate nanosensor also in vivo in mice (Mächler et al., 2016) and Drosophila (Liu et al., 2017) and was shown to be impaired in the in vivo mice models of Alzheimer's disease (Sun et al., 2020).

Astroglial-derived extracellular L-lactate may also act extracellularly as a signaling molecule, activating LLRs on the surface of neural cells as discussed in the previous section (Table 1; Tang et al., 2014; Mosienko et al., 2015, 2018; Vardjan et al., 2018; D'Adamo et al., 2021). L-Lactate released from astrocytes was shown to excite noradrenergic neurons via AC-mediated cAMP signaling to release noradrenaline, which can then back-excite astrocytes (Tang et al., 2014). Activation of astroglial $\alpha_{1}$ - and $\beta$-adrenergic receptors and intracellular $\mathrm{Ca}^{2+}$ and cAMP signals by noradrenaline is known to upregulate glucose uptake, glycogenolysis, and aerobic glycolysis in astrocytes, which can lead to more L-lactate production and release (Sorg and Magistretti, 1991; Gibbs, 2015; Horvat et al., 2017; Vardjan et al., 2018; Velebit et al., 2020; Fink et al., 2021). Moreover, extracellular L-lactate $(20 \mathrm{mM})$, as well as GPR81 agonist 3Cl-5OH-BA $(0.5 \mathrm{mM})$, were shown to upregulate aerobic glycolysis and L-lactate production in isolated cortical astrocytes as measured by Laconic, a FRET-based lactate nanosensor (Vardjan et al., 2018; D'Adamo et al., 2021). 3Cl-5OHBA-induced L-lactate production in astrocytes was greatly reduced in the presence of $\mathrm{AC}$ inhibitor DDA $(100 \mu \mathrm{M})$, suggesting the involvement of a $\mathrm{G}_{\mathrm{s}}$-protein coupled LLR and cAMP signals in the regulation of L-lactate-induced aerobic glycolysis in astrocytes (Vardjan et al., 2018; D'Adamo et al., 2021; Figure 1).

Compared with noradrenaline $(200 \mu \mathrm{M})$, which increases cytosolic free $\mathrm{D}$-glucose concentration via activation of $\alpha_{1}$ adrenergic receptors and $\mathrm{Ca}^{2+}$ signaling due to $\mathrm{Ca}^{2+}$-driven extracellular D-glucose uptake (Prebil et al., 2011; Vardjan et al., 2018; D’Adamo et al., 2021; Horvat et al., 2021), L-lactate $(20 \mathrm{mM})$ and $3 \mathrm{Cl}-5 \mathrm{OH}-\mathrm{BA}(0.5 \mathrm{mM})$ decrease cytosolic free D-glucose in astrocytes, as measured with FLII $^{12}$ Pglu- $700 \mu \delta 6$, a genetically encoded FRET-based glucose nanosensor (Table 1; Vardjan et al., 2018). This is consistent with the fact that extracellular free $\mathrm{D}$-glucose uptake depends primarily on $\mathrm{Ca}^{2+}$ signals but not cAMP signals (Horvat et al., 2021), and the fact that extracellular L-lactate and GPR81 agonists trigger increases in cAMP signals but not $\mathrm{Ca}^{2+}$ signals in astrocytes (Vardjan et al., 2018; D'Adamo et al., 2021). The observed decrease in cytosolic D-glucose levels in astrocytes exposed to extracellular L-lactate or 3Cl-5OH-BA most likely indicates entry of free $\mathrm{D}$-glucose into the glycolytic pathway.

Thus, L-lactate released from astrocytes may not only activate neurons but may also act in an autocrine manner augmenting its own production in astrocytes. This new positive feedback mechanism of receptor-mediated L-lactate signaling ("metabolic excitability"; Vardjan et al., 2018) that controls astroglial L-lactate production may serve to maintain high intracellular levels of L-lactate, facilitating L-lactate release and thereby generating a concentration gradient between astrocytes and neurons to provide a continuous source of L-lactate to support neural network activity (Mächler et al., 2016; Figure 1). However, because relatively high concentrations of L-lactate $(20 \mathrm{mM})$ are needed to facilitate CAMP-mediated aerobic glycolysis (Vardjan et al., 2018; D'Adamo et al., 2021), the new putative astroglial excitatory LLR mechanisms may be particularly relevant under supraphysiologic and pathologic conditions (i.e., ischemia and epilepsy; During et al., 1994; Mosienko et al., 2015), during exercise (Matsui et al., 2017), or at the sites of local extracellular L-lactate increases (L-lactate production in microdomains), if they exist, which needs to be studied in the future (Bergersen and Gjedde, 2012).

\section{L-LACTATE AND THE CONTROL OF BRAIN LIPID METABOLISM}

Regulation of brain glucose metabolism has been in the spotlight of the research community for a long time, but the importance of lipid metabolism in brain function has only gained attention in recent years (Panov et al., 2014).

Glial-neuronal coupling of glucose and lipid metabolism was recently suggested to occur as a response to neural activity to protect neurons from lipotoxicity (Liu et al., 2017; Ioannou et al., 2019). The mechanism proposes that L-lactate transport from astrocytes to neurons via ANLS triggers de novo synthesis of free fatty acids (FFAs) from L-lactate in stressed overstimulated neurons. L-Lactate is decarboxylated in neuronal mitochondria and the resulting acetyl-CoA generates FFAs. Excess of FFAs in neurons is associated with the lipid peroxidation chain reaction and generation of reactive oxygen species (ROS), which may lead to lipotoxicity. To avoid lipotoxicity, excess FFAs are considered to be transferred from neurons to glial cells, particularly astrocytes, in vesicles containing apolipoprotein E-like particles, where they are stored in lipid droplets (LDs; Liu et al., 2015, 2017; Ioannou et al., 2019). FFAs stored in LDs can be used by astrocytes as an energy substrate in $\beta$-oxidation (Ioannou et al., 2019), because astrocytes have the capacity to fight mitochondrial overproduction of ROS during $\beta$-oxidation. Recently, it was shown that chronic ( $24 \mathrm{~h}$ ) exposure of both tissue astrocytes and isolated cortical astrocytes in the absence of neurons to $20 \mathrm{mM}$ extracellular L-lactate (Smolic et al., 2021) triggers LD accumulation in astrocytes (Table 1). This suggests the existence of an alternative L-lactate-mediated mechanism augmenting LD accumulation in astrocytes. Extracellular L-lactate could affect LD turnover in astrocytes by entering cells via MCTs and/or ion channels (Sotelo-Hitschfeld et al., 2015), where L-lactate acts as a substrate for de novo FFA synthesis, as shown in oligodendrocytes (Sánchez-Abarca et al., 2001) and neurons (Liu et al., 2017; Ioannou et al., 2019), leading to excess FFA production and FFA storage in LDs to protect astrocytes from lipotoxicity. But extracellular 
L-lactate may also trigger LD accumulation in astrocytes through actions via plasmalemmal LLRs, which needs to be investigated in more detail in the future.

\section{CONCLUSION AND PERSPECTIVES}

In conclusion, it is now well established that multiple brain functions are either supported or modulated by L-lactate acting either as a metabolic substrate or signaling molecule. The discovery of signaling properties of L-lactate in astrocytes that are manifested as upregulation in intracellular cAMP production, suggests the existence of a new, as yet unidentified, L-lactate sensitive GPCR coupled to $\mathrm{G}_{\mathrm{s}}$-proteins in astrocytes. L-Lactatetriggered CAMP signals in astrocytes facilitate aerobic glycolysis with more L-lactate production (metabolic excitability), likely to provide neurons with more L-lactate. Moreover, chronic exposure to L-lactate triggers accumulation of LDs in astrocytes, suggesting that astrocytes switch to lipid metabolism. However, this is achieved only at relatively high extracellular concentrations

\section{REFERENCES}

Abi-Saab, W. M., Maggs, D. G., Jones, T., Jacob, R., Srihari, V., Thompson, J., et al. (2002). Striking differences in glucose and lactate levels between brain extracellular fluid and plasma in conscious human subjects: effects of hyperglycemia and hypoglycemia. J. Cereb. Blood Flow Metab. 22, 271-279. doi: 10.1097/00004647-200203000-00004

Afridi, R., Kim, J.-H., Rahman, M. H., and Suk, K. (2020). Metabolic regulation of glial phenotypes: implications in neuron-glia interactions and neurological disorders. Front. Cell. Neurosci. 14:20. doi: 10.3389/fncel.2020.00020

Ahmed, K., Tunaru, S., Tang, C., Müller, M., Gille, A., Sassmann, A., et al. (2010). An autocrine lactate loop mediates insulin-dependent inhibition of lipolysis through GPR81. Cell Metab. 11, 311-319. doi: 10.1016/j. cmet.2010.02.012

Almeida, A., Moncada, S., and Bolaños, J. P. (2004). Nitric oxide switches on glycolysis through the AMP protein kinase and 6-phosphofructo-2-kinase pathway. Nat. Cell Biol. 6, 45-51. doi: 10.1038/ncb1080

Bak, L. K., Walls, A. B., Schousboe, A., and Waagepetersen, H. S. (2018). Astrocytic glycogen metabolism in the healthy and diseased brain. J. Biol. Chem. 293, 7108-7116. doi: 10.1074/jbc.R117.803239

Baltazar, F., Afonso, J., Costa, M., and Granja, S. (2020). Lactate beyond a waste metabolite: metabolic affairs and signaling in malignancy. Front. Oncol. 10:231. doi: 10.3389/fonc.2020.00231

Barros, L. F. (2013). Metabolic signaling by lactate in the brain. Trends Neurosci. 36, 396-404. doi: 10.1016/j.tins.2013.04.002

Bekar, L. K., He, W., and Nedergaard, M. (2008). Locus coeruleus alphaadrenergic-mediated activation of cortical astrocytes in vivo. Cereb. Cortex 18, 2789-2795. doi: 10.1093/cercor/bhn040

Bélanger, M., Allaman, I., and Magistretti, P. J. (2011). Brain energy metabolism: focus on astrocyte-neuron metabolic cooperation. Cell Metab. 14, 724-738. doi: 10.1016/j.cmet.2011.08.016

Bergersen, L. H. (2015). Lactate transport and signaling in the brain: potential therapeutic targets and roles in body-brain interaction. J. Cereb. Blood Flow Metab. 35, 176-185. doi: 10.1038/jcbfm.2014.206

Bergersen, L. H., and Gjedde, A. (2012). Is lactate a volume transmitter of metabolic states of the brain? Front. Neuroenerg. 4:5. doi: 10.3389/ fnene.2012.00005

Berthet, C., Castillo, X., Magistretti, P. J., and Hirt, L. (2012). New evidence of neuroprotection by lactate after transient focal cerebral ischaemia: extended benefit after intracerebroventricular injection and efficacy of intravenous administration. Cerebrovasc. Dis. 34, 329-335. doi: 10.1159/ 000343657 of L-lactate, implying a role of L-lactate signaling in astrocytes particularly at the sites of putative L-lactate microdomains, under pathologic conditions, or during exercise. Identification of L-lactate-sensitive GPCRs in astrocytes and increasing knowledge on this topic will provide further insights into our understanding of the importance of L-lactate signals in the regulation of brain metabolism and support of brain performance.

\section{AUTHOR CONTRIBUTIONS}

All authors listed have made a substantial, direct and intellectual contribution to the work, and approved it for publication.

\section{FUNDING}

The work was supported by grants from the Slovenian Research Agency (P3-0310, J3-6790, J3-9266, and J3-2523) and COST Action CA18133 (ERNEST).

Bittner, C. X., Valdebenito, R., Ruminot, I., Loaiza, A., Larenas, V., Sotelo-Hitschfeld, T., et al. (2011). Fast and reversible stimulation of astrocytic glycolysis by $\mathrm{K}+$ and a delayed and persistent effect of glutamate. J. Neurosci. 31, 4709-4713. doi: 10.1523/jneurosci.5311-10.2011

Boumezbeur, F., Petersen, K. F., Cline, G. W., Mason, G. F., Behar, K. L., Shulman, G. I., et al. (2010). The contribution of blood lactate to brain energy metabolism in humans measured by dynamic 13C nuclear magnetic resonance spectroscopy. J. Neurosci. 30, 13983-13991. doi: 10.1523/ jneurosci.2040-10.2010

Bozzo, L., Puyal, J., and Chatton, J. Y. (2013). Lactate modulates the activity of primary cortical neurons through a receptor-mediated pathway. PLoS One 8:e71721. doi: 10.1371/journal.pone.0071721

Cai, T. Q., Ren, N., Jin, L., Cheng, K., Kash, S., Chen, R., et al. (2008). Role of GPR81 in lactate-mediated reduction of adipose lipolysis. Biochem. Biophys. Res. Commun. 377, 987-991. doi: 10.1016/j.bbrc.2008.10.088

Carrard, A., Elsayed, M., Margineanu, M., Boury-Jamot, B., Fragnière, L., Meylan, E. M., et al. (2018). Peripheral administration of lactate produces antidepressant-like effects. Mol. Psychiatry 23, 392-399. doi: 10.1038/ mp.2016.179

Castillo, X., Rosafio, K., Wyss, M. T., Drandarov, K., Buck, A., Pellerin, L. et al. (2015). A probable dual mode of action for both L- and D-lactate neuroprotection in cerebral ischemia. J. Cereb. Blood Flow Metab. 35, 1561-1569. doi: $10.1038 /$ jcbfm.2015.115

Chang, A. J., Ortega, F. E., Riegler, J., Madison, D. V., and Krasnow, M. A (2015). Oxygen regulation of breathing through an olfactory receptor activated by lactate. Nature 527, 240-244. doi: 10.1038/nature15721

Chatton, J. Y., Magistretti, P. J., and Barros, L. F. (2016). Sodium signaling and astrocyte energy metabolism. Glia 64, 1667-1676. doi: 10.1002/glia.22971

Choi, H. B., Gordon, G. R., Zhou, N., Tai, C., Rungta, R. L., Martinez, J., et al. (2012). Metabolic communication between astrocytes and neurons via bicarbonate-responsive soluble adenylyl cyclase. Neuron 75, 1094-1104. doi: 10.1016/j.neuron.2012.08.032

Conzelmann, S., Levai, O., Bode, B., Eisel, U., Raming, K., Breer, H., et al. (2000). A novel brain receptor is expressed in a distinct population of olfactory sensory neurons. Eur. J. Neurosci. 12, 3926-3934. doi: 10.1046/j.1460-9568.2000.00286.x

Curie, A., Sacco, S., Bussy, G., de Saint Martin, A., Boddaert, N., Chanraud, S., et al. (2009). Impairment of cerebello-thalamo-frontal pathway in Rab-GDI mutated patients with pure mental deficiency. Eur. J. Med. Genet. 52, 6-13. doi: 10.1016/j.ejmg.2008.09.003

D’Adamo, P., Horvat, A., Gurgone, A., Mignogna, M. L., Bianchi, V., Masetti, M., et al. (2021). Inhibiting glycolysis rescues memory impairment in an intellectual 
disability Gdi1-null mouse. Metabolism 116:154463. doi: 10.1016/j. metabol.2020.154463

Descalzi, G., Gao, V., Steinman, M. Q., Suzuki, A., and Alberini, C. M. (2019). Lactate from astrocytes fuels learning-induced mRNA translation in excitatory and inhibitory neurons. Commun. Biol. 2:247. doi: 10.1038/s42003-019-0495-2

Díaz-García, C. M., Mongeon, R., Lahmann, C., Koveal, D., Zucker, H., and Yellen, G. (2017). Neuronal stimulation triggers neuronal glycolysis and not lactate uptake. Cell Metab. 26, 361-374.e364. doi: 10.1016/j.cmet.2017.06.021

Dienel, G. A. (2012a). Brain lactate metabolism: the discoveries and the controversies. J. Cereb. Blood Flow Metab. 32, 1107-1138. doi: 10.1038/ jcbfm.2011.175

Dienel, G. A. (2012b). Fueling and imaging brain activation. ASN Neuro 4:e00093. doi: $10.1042 /$ an 20120021

Dienel, G. A. (2017). Lack of appropriate stoichiometry: strong evidence against an energetically important astrocyte-neuron lactate shuttle in brain. J. Neurosci. Res. 95, 2103-2125. doi: 10.1002/jnr.24015

Dienel, G. A. (2019). Does shuttling of glycogen-derived lactate from astrocytes to neurons take place during neurotransmission and memory consolidation? J. Neurosci. Res. 97, 863-882. doi: 10.1002/jnr.24387

Dienel, G. A., and Cruz, N. F. (2016). Aerobic glycolysis during brain activation: adrenergic regulation and influence of norepinephrine on astrocytic metabolism. J. Neurochem. 138, 14-52. doi: 10.1111/jnc. 13630

Ding, F., O’Donnell, J., Thrane, A. S., Zeppenfeld, D., Kang, H., Xie, L., et al. (2013). $\alpha 1$-adrenergic receptors mediate coordinated $\mathrm{Ca} 2+$ signaling of cortical astrocytes in awake, behaving mice. Cell Calcium 54, 387-394. doi: 10.1016/j. ceca.2013.09.001

During, M. J., Fried, I., Leone, P., Katz, A., and Spencer, D. D. (1994). Direct measurement of extracellular lactate in the human hippocampus during spontaneous seizures. J. Neurochem. 62, 2356-2361. doi: 10.1046/j.1471-4159.1994.62062356.x

Dvorak, C. A., Liu, C., Shelton, J., Kuei, C., Sutton, S. W., Lovenberg, T. W., et al. (2012). Identification of hydroxybenzoic acids as selective lactate receptor (GPR81) agonists with antilipolytic effects. ACS Med. Chem. Lett. 3, 637-639. doi: $10.1021 / \mathrm{ml} 3000676$

Feng, J., Yang, H., Zhang, Y., Wei, H., Zhu, Z., Zhu, B., et al. (2017). Tumor cell-derived lactate induces TAZ-dependent upregulation of PD-L1 through GPR81 in human lung cancer cells. Oncogene 36, 5829-5839. doi: 10.1038/ onc.2017.188

Fink, K., Velebit, J., Vardjan, N., Zorec, R., and Kreft, M. (2021). Noradrenalineinduced 1-lactate production requires d-glucose entry and transit through the glycogen shunt in single-cultured rat astrocytes. J. Neurosci. Res. 99, 1084-1098. doi: 10.1002/jnr.24783

Fünfschilling, U., Supplie, L. M., Mahad, D., Boretius, S., Saab, A. S., Edgar, J., et al. (2012). Glycolytic oligodendrocytes maintain myelin and long-term axonal integrity. Nature 485, 517-521. doi: 10.1038/nature11007

Gibbs, M. E. (2015). Role of glycogenolysis in memory and learning: regulation by noradrenaline, serotonin and ATP. Front. Integr. Neurosci. 9:70. doi: $10.3389 /$ fnint.2015.00070

Gordon, G. R., Choi, H. B., Rungta, R. L., Ellis-Davies, G. C., and MacVicar, B. A. (2008). Brain metabolism dictates the polarity of astrocyte control over arterioles. Nature 456, 745-749. doi: 10.1038/nature07525

Hertz, L., Gibbs, M. E., and Dienel, G. A. (2014). Fluxes of lactate into, from, and among gap junction-coupled astrocytes and their interaction with noradrenaline. Front. Neurosci. 8:261. doi: 10.3389/fnins.2014.00261

Hertz, L., Lovatt, D., Goldman, S. A., and Nedergaard, M. (2010). Adrenoceptors in brain: cellular gene expression and effects on astrocytic metabolism and [ca(2+)]i. Neurochem. Int. 57, 411-420. doi: 10.1016/j.neuint.2010.03.019

Hertz, L., Xu, J., Song, D., Du, T., Li, B., Yan, E., et al. (2015). Astrocytic glycogenolysis: mechanisms and functions. Metab. Brain Dis. 30, 317-333. doi: 10.1007/s11011-014-9536-1

Hertz, L., Xu, J., Song, D., Du, T., Yan, E., and Peng, L. (2013). Brain glycogenolysis, adrenoceptors, pyruvate carboxylase, $\mathrm{Na}(+), \mathrm{K}(+)$-ATPase and Marie E. Gibbs' pioneering learning studies. Front. Integr. Neurosci. 7:20. doi: 10.3389/ fnint.2013.00020

Horvat, A., Muhič, M., Smolič, T., Begić, E., Zorec, R., Kreft, M., et al. (2021). $\mathrm{Ca} 2+$ as the prime trigger of aerobic glycolysis in astrocytes. Cell Calcium 95:102368. doi: 10.1016/j.ceca.2021.102368

Horvat, A., Vardjan, N., and Zorec, R. (2017). Targeting astrocytes for treating neurological disorders: carbon monoxide and noradrenaline-induced increase in lactate. Curr. Pharm. Des. 23, 4969-4978. doi: 10.217 4/1381612823666170622112734

Horvat, A., Zorec, R., and Vardjan, N. (2016). Adrenergic stimulation of single rat astrocytes results in distinct temporal changes in intracellular $\mathrm{ca}(2+)$ and cAMP-dependent PKA responses. Cell Calcium 59, 156-163. doi: 10.1016/j. ceca.2016.01.002

Hosford, P. S., Mosienko, V., Kishi, K., Jurisic, G., Seuwen, K., Kinzel, B., et al. (2018). CNS distribution, signalling properties and central effects of G-protein coupled receptor 4. Neuropharmacology 138, 381-392. doi: 10.1016/j. neuropharm.2018.06.007

Hung, Y. P., Albeck, J. G., Tantama, M., and Yellen, G. (2011). Imaging cytosolic $\mathrm{NADH}-\mathrm{NAD}(+)$ redox state with a genetically encoded fluorescent biosensor. Cell Metab. 14, 545-554. doi: 10.1016/j.cmet.2011.08.012

Ioannou, M. S., Jackson, J., Sheu, S. H., Chang, C. L., Weigel, A. V., Liu, H., et al. (2019). Neuron-astrocyte metabolic coupling protects against activityinduced fatty acid toxicity. Cell 177, 1522-1535.e1514. doi: 10.1016/j. cell.2019.04.001

Karagiannis, A., Sylantyev, S., Hadjihambi, A., Hosford, P. S., Kasparov, S., and Gourine, A. V. (2016). Hemichannel-mediated release of lactate. J. Cereb. Blood Flow Metab. 36, 1202-1211. doi: 10.1177/0271678x15611912

Lauritzen, K. H., Morland, C., Puchades, M., Holm-Hansen, S., Hagelin, E. M., Lauritzen, F., et al. (2014). Lactate receptor sites link neurotransmission, neurovascular coupling, and brain energy metabolism. Cereb. Cortex 24, 2784-2795. doi: 10.1093/cercor/bht136

Lee, D. C., Sohn, H. A., Park, Z.-Y., Oh, S., Kang, Y. K., Lee, K.-M., et al. (2015). A lactate-induced response to hypoxia. Cell 161, 595-609. doi: 10.1016/j.cell.2015.03.011

Lerchundi, R., Fernández-Moncada, I., Contreras-Baeza, Y., Sotelo-Hitschfeld, T., Mächler, P., Wyss, M. T., et al. (2015). NH4(+) triggers the release of astrocytic lactate via mitochondrial pyruvate shunting. Proc. Natl. Acad. Sci. U. S. A. 112, 11090-11095. doi: 10.1073/pnas. 1508259112

Liu, C., Kuei, C., Zhu, J., Yu, J., Zhang, L., Shih, A., et al. (2012). 3,5-Dihydroxybenzoic acid, a specific agonist for hydroxycarboxylic acid 1, inhibits lipolysis in adipocytes. J. Pharmacol. Exp. Ther. 341, 794-801. doi: 10.1124/jpet.112.192799

Liu, L., MacKenzie, K. R., Putluri, N., Maletic-Savatic, M., and Bellen, H. J. (2017). The glia-neuron lactate shuttle and elevated ros promote lipid synthesis in neurons and lipid droplet accumulation in glia via APOE/D. Cell Metab. 26, 719-737.e716. doi: 10.1016/j.cmet.2017.08.024

Liu, C., Wu, J., Zhu, J., Kuei, C., Yu, J., Shelton, J., et al. (2009). Lactate inhibits lipolysis in fat cells through activation of an orphan G-proteincoupled receptor, GPR81. J. Biol. Chem. 284, 2811-2822. doi: 10.1074/jbc. M806409200

Liu, L., Zhang, K., Sandoval, H., Yamamoto, S., Jaiswal, M., Sanz, E., et al. (2015). Glial lipid droplets and ROS induced by mitochondrial defects promote neurodegeneration. Cell 160, 177-190. doi: 10.1016/j.cell.2014.12.019

Mächler, P., Wyss, M. T., Elsayed, M., Stobart, J., Gutierrez, R., von Faber-Castell, A., et al. (2016). In vivo evidence for a lactate gradient from astrocytes to neurons. Cell Metab. 23, 94-102. doi: 10.1016/j.cmet.2015.10.010

Magistretti, P. J., and Allaman, I. (2015). A cellular perspective on brain energy metabolism and functional imaging. Neuron 86, 883-901. doi: 10.1016/j. neuron.2015.03.035

Magistretti, P. J., and Allaman, I. (2018). Lactate in the brain: from metabolic end-product to signalling molecule. Nat. Rev. Neurosci. 19, 235-249. doi: 10.1038/nrn.2018.19

Matsui, T., Omuro, H., Liu, Y. F., Soya, M., Shima, T., McEwen, B. S., et al. (2017). Astrocytic glycogen-derived lactate fuels the brain during exhaustive exercise to maintain endurance capacity. Proc. Natl. Acad. Sci. U. S. A. 114, 6358-6363. doi: 10.1073/pnas.1702739114

Morland, C., Andersson, K. A., Haugen, Ø. P., Hadzic, A., Kleppa, L., Gille, A., et al. (2017). Exercise induces cerebral VEGF and angiogenesis via the lactate receptor HCAR1. Nat. Commun. 8:15557. doi: 10.1038/ncomms15557

Morland, C., Lauritzen, K. H., Puchades, M., Holm-Hansen, S., Andersson, K., Gjedde, A., et al. (2015). The lactate receptor, G-protein-coupled receptor 81/hydroxycarboxylic acid receptor 1: expression and action in brain. J. Neurosci. Res. 93, 1045-1055. doi: 10.1002/jnr.23593

Mosienko, V., Chang, A. J., Alenina, N., Teschemacher, A. G., and Kasparov, S. (2017). Rodents and humans are able to detect the odour of L-lactate. PLoS One 12:e178478. doi: 10.1371/journal.pone.0178478 
Mosienko, V., Rasooli-Nejad, S., Kishi, K., De Both, M., Jane, D., Huentelman, M., et al. (2018). Putative receptors underpinning L-lactate signalling in locus coeruleus. Neuroglia 1, 365-380. doi: 10.3390/neuroglia1020025

Mosienko, V., Teschemacher, A. G., and Kasparov, S. (2015). Is L-lactate a novel signaling molecule in the brain? J. Cereb. Blood Flow Metab. 35, 1069-1075. doi: $10.1038 /$ jcbfm.2015.77

Murphy-Royal, C., Johnston, A. D., Boyce, A. K. J., Diaz-Castro, B., Institoris, A., Peringod, G., et al. (2020). Stress gates an astrocytic energy reservoir to impair synaptic plasticity. Nat. Commun. 11:2014. doi: 10.1038/ s41467-020-15778-9

Nedergaard, M., and Goldman, S. A. (1993). Carrier-mediated transport of lactic acid in cultured neurons and astrocytes. Am. J. Phys. 265, R282-R289. doi: 10.1152/ajpregu.1993.265.2.R282

Newman, L. A., Korol, D. L., and Gold, P. E. (2011). Lactate produced by glycogenolysis in astrocytes regulates memory processing. PLoS One 6:e28427. doi: 10.1371/journal.pone.0028427

O'Donnell, J., Zeppenfeld, D., McConnell, E., Pena, S., and Nedergaard, M. (2012). Norepinephrine: a neuromodulator that boosts the function of multiple cell types to optimize CNS performance. Neurochem. Res. 37, 2496-2512. doi: 10.1007/s11064-012-0818-x

Ohbuchi, T., Sato, K., Suzuki, H., Okada, Y., Dayanithi, G., Murphy, D., et al. (2010). Acid-sensing ion channels in rat hypothalamic vasopressin neurons of the supraoptic nucleus. J. Physiol. 588, 2147-2162. doi: 10.1113/ jphysiol.2010.187625

Oz, G., DiNuzzo, M., Kumar, A., Moheet, A., and Seaquist, E. R. (2015). Revisiting glycogen content in the human brain. Neurochem. Res. 40, 2473-2481. doi: 10.1007/s11064-015-1664-4

Panov, A., Orynbayeva, Z., Vavilin, V., and Lyakhovich, V. (2014). Fatty acids in energy metabolism of the central nervous system. Biomed. Res. Int. 2014:472459. doi: 10.1155/2014/472459

Parsons, M. P., and Hirasawa, M. (2010). ATP-sensitive potassium channelmediated lactate effect on orexin neurons: implications for brain energetics during arousal. J. Neurosci. 30, 8061-8070. doi: 10.1523/ JNEUROSCI.5741-09.2010

Pellerin, L., and Magistretti, P. J. (1994). Glutamate uptake into astrocytes stimulates aerobic glycolysis: a mechanism coupling neuronal activity to glucose utilization. Proc. Natl. Acad. Sci. U. S. A. 91, 10625-10629.

Pellerin, L., and Magistretti, P. J. (1996). Excitatory amino acids stimulate aerobic glycolysis in astrocytes via an activation of the $\mathrm{Na}+\mathrm{K}+$ ATPase. Dev. Neurosci. 18, 336-342. doi: 10.1159/000111426

Pellerin, L., and Magistretti, P. J. (2012). Sweet sixteen for ANLS. J. Cereb. Blood Flow Metab. 32, 1152-1166. doi: 10.1038/jcbfm.2011.149

Pérez-Escuredo, J., Van Hée, V. F., Sboarina, M., Falces, J., Payen, V. L., Pellerin, L., et al. (2016). Monocarboxylate transporters in the brain and in cancer. Biochim. Biophys. Acta 1863, 2481-2497. doi: 10.1016/j. bbamcr.2016.03.013

Prebil, M., Vardjan, N., Jensen, J., Zorec, R., and Kreft, M. (2011). Dynamic monitoring of cytosolic glucose in single astrocytes. Glia 59, 903-913. doi: 10.1002/glia.21161

Requardt, R. P., Hirrlinger, P. G., Wilhelm, F., Winkler, U., Besser, S., and Hirrlinger, J. (2012). Ca2+ signals of astrocytes are modulated by the NAD+l NADH redox state. J. Neurochem. 120, 1014-1025. doi: 10.1111/j.1471-4159.2012.07645.x

Roland, C. L., Arumugam, T., Deng, D., Liu, S. H., Philip, B., Gomez, S., et al. (2014). Cell surface lactate receptor GPR81 is crucial for cancer cell survival. Cancer Res. 74, 5301-5310. doi: 10.1158/0008-5472.CAN-14-0319

Rooney, K., and Trayhurn, P. (2011). Lactate and the GPR81 receptor in metabolic regulation: implications for adipose tissue function and fatty acid utilisation by muscle during exercise. Br. J. Nutr. 106, 1310-1316. doi: 10.1017/ s0007114511004673

Ros, J., Pecinska, N., Alessandri, B., Landolt, H., and Fillenz, M. (2001). Lactate reduces glutamate-induced neurotoxicity in rat cortex. J. Neurosci. Res. 66, 790-794. doi: 10.1002/jnr.10043

Rose, C. R., and Verkhratsky, A. (2016). Principles of sodium homeostasis and sodium signalling in astroglia. Glia 64, 1611-1627. doi: 10.1002/glia.22964

Ruminot, I., Gutiérrez, R., Peña-Münzenmayer, G., Añazco, C., Sotelo-Hitschfeld, T., Lerchundi, R., et al. (2011). NBCel mediates the acute stimulation of astrocytic glycolysis by extracellular K+. J. Neurosci. 31, 14264-14271. doi: 10.1523/jneurosci.2310-11.2011
Saab, A. S., Tzvetavona, I. D., Trevisiol, A., Baltan, S., Dibaj, P., Kusch, K., et al. (2016). Oligodendroglial NMDA receptors regulate glucose import and axonal energy metabolism. Neuron 91, 119-132. doi: 10.1016/j. neuron.2016.05.016

Sakurai, T., Davenport, R., Stafford, S., Grosse, J., Ogawa, K., Cameron, J., et al. (2014). Identification of a novel GPR81-selective agonist that suppresses lipolysis in mice without cutaneous flushing. Eur. J. Pharmacol. 727, 1-7. doi: 10.1016/j.ejphar.2014.01.029

San Martín, A., Arce-Molina, R., Galaz, A., Pérez-Guerra, G., and Barros, L. F. (2017). Nanomolar nitric oxide concentrations quickly and reversibly modulate astrocytic energy metabolism. J. Biol. Chem. 292, 9432-9438. doi: 10.1074/ jbc.M117.777243

Sánchez-Abarca, L. I., Tabernero, A., and Medina, J. M. (2001). Oligodendrocytes use lactate as a source of energy and as a precursor of lipids. Glia 36, 321-329. doi: 10.1002/glia.1119

Scemes, E., Stout, R. F., and Spray, D. C. (2017). "Adrenergic receptors on astrocytes modulate gap junctions," in Noradrenergic Signaling and Astroglia. 1st Edn. eds. N. Vardjan and R. Zorec (Mara Conner: Academic Press, Elsevier), 342.

Sharma, K., Schmitt, S., Bergner, C. G., Tyanova, S., Kannaiyan, N., Manrique-Hoyos, N., et al. (2015). Cell type- and brain region-resolved mouse brain proteome. Nat. Neurosci. 18, 1819-1831. doi: 10.1038/nn.4160

Smith, M. L., von Hanwehr, R., and Siesjö, B. K. (1986). Changes in extraand intracellular $\mathrm{pH}$ in the brain during and following ischemia in hyperglycemic and in moderately hypoglycemic rats. J. Cereb. Blood Flow Metab. 6, 574-583. doi: 10.1038/jcbfm.1986.104

Smolič, T., Tavčar, P., Horvat, A., Černe, U., Halužan Vasle, A., Tratnjek, L., et al. (2021). Astrocytes in stress accumulate lipid droplets. Glia 69, 1540-1562. doi: $10.1002 /$ glia.23978

Song, Z., and Routh, V. H. (2005). Differential effects of glucose and lactate on glucosensing neurons in the ventromedial hypothalamic nucleus. Diabetes 54, 15-22. doi: 10.2337/diabetes.54.1.15

Sorg, O., and Magistretti, P. J. (1991). Characterization of the glycogenolysis elicited by vasoactive intestinal peptide, noradrenaline and adenosine in primary cultures of mouse cerebral cortical astrocytes. Brain Res. 563, 227-233. doi: 10.1016/0006-8993(91)91538-C

Sotelo-Hitschfeld, T., Niemeyer, M. I., Mächler, P., Ruminot, I., Lerchundi, R., Wyss, M. T., et al. (2015). Channel-mediated lactate release by $\mathrm{K}^{+}$-stimulated astrocytes. J. Neurosci. 35, 4168-4178. doi: 10.1523/JNEUROSCI.5036-14.2015

Stenmark, H. (2009). Rab GTPases as coordinators of vesicle traffic. Nat. Rev. Mol. Cell Biol. 10, 513-525. doi: 10.1038/nrm 2728

Sun, Y., Wang, Y., Chen, S.-T., Chen, Y.-J., Shen, J., Yao, W.-B., et al. (2020). Modulation of the astrocyte-neuron lactate shuttle system contributes to neuroprotective action of fibroblast growth factor 21. Theranostics 10, 8430-8445. doi: $10.7150 /$ thno. 44370

Sun, J., Ye, X., Xie, M., and Ye, J. (2016). Induction of triglyceride accumulation and mitochondrial maintenance in muscle cells by lactate. Sci. Rep. 6:33732. doi: $10.1038 /$ srep 33732

Suzuki, A., Stern, S. A., Bozdagi, O., Huntley, G. W., Walker, R. H., Magistretti, P. J., et al. (2011). Astrocyte-neuron lactate transport is required for long-term memory formation. Cell 144, 810-823. doi: 10.1016/j.cell.2011.02.018

Tang, F., Lane, S., Korsak, A., Paton, J. F., Gourine, A. V., Kasparov, S., et al. (2014). Lactate-mediated glia-neuronal signalling in the mammalian brain. Nat. Commun. 5:3284. doi: 10.1038/ncomms4284

Vander Heiden, M. G., Cantley, L. C., and Thompson, C. B. (2009). Understanding the Warburg effect: the metabolic requirements of cell proliferation. Science 324, 1029-1033. doi: 10.1126/science.1160809

Vardjan, N., Chowdhury, H. H., Horvat, A., Velebit, J., Malnar, M., Muhič, M., et al. (2018). Enhancement of astroglial aerobic glycolysis by extracellular lactate-mediated increase in cAMP. Front. Mol. Neurosci. 11:148. doi: 10.3389/ fnmol.2018.00148

Vardjan, N., Kreft, M., and Zorec, R. (2014). Dynamics of $\beta$-adrenergic/cAMP signaling and morphological changes in cultured astrocytes. Glia 62, 566-579. doi: $10.1002 /$ glia. 22626

Vardjan, N., and Zorec, R. (2015). Excitable astrocytes: ca(2+)- and cAMPregulated exocytosis. Neurochem. Res. 40, 2414-2424. doi: 10.1007/ s11064-015-1545-x

Vardjan, N., and Zorec, R. (2017). Noradrenergic Signaling and Astroglia. Mara Conner: Academic Press, Elsevier. 
Velebit, J., Horvat, A., Smolič, T., Prpar Mihevc, S., Rogelj, B., Zorec, R., et al. (2020). Astrocytes with TDP-43 inclusions exhibit reduced noradrenergic cAMP and Ca2+ signaling and dysregulated cell metabolism. Sci. Rep. 10:6003. doi: 10.1038/s41598-020-62864-5

Verkhratsky, A., and Nedergaard, M. (2018). Physiology of Astroglia. Physiol. Rev. 98, 239-389. doi: 10.1152/physrev.00042.2016

Warburg, O. (1956). On the origin of cancer cells. Science 123, 309-314. doi: 10.1126/science.123.3191.309

Yang, S., Qin, C., Hu, Z.-W., Zhou, L.-Q., Yu, H.-H., Chen, M., et al. (2021). Microglia reprogram metabolic profiles for phenotype and function changes in central nervous system. Neurobiol. Dis. 152:105290. doi: 10.1016/j.nbd.2021.105290

Yang, J., Ruchti, E., Petit, J. M., Jourdain, P., Grenningloh, G., Allaman, I., et al. (2014). Lactate promotes plasticity gene expression by potentiating NMDA signaling in neurons. Proc. Natl. Acad. Sci. U. S. A. 111, 12228-12233. doi: 10.1073/pnas.1322912111

Yang, F., Sun, X., Ding, Y., Ma, H., Yang, T. O., Ma, Y., et al. (2016). Astrocytic acid-sensing ion channel la contributes to the development of chronic epileptogenesis. Sci. Rep. 6:31581. doi: 10.1038/srep31581

Zhang, Y., Chen, K., Sloan, S. A., Bennett, M. L., Scholze, A. R., O'Keeffe, S., et al. (2014). An RNA-sequencing transcriptome and splicing database of glia, neurons, and vascular cells of the cerebral cortex. J. Neurosci. 34, 11929-11947. doi: 10.1523/JNEUROSCI.1860-14.2014
Zhang, Y., Sloan, S. A., Clarke, L. E., Caneda, C., Plaza, C. A., Blumenthal, P. D., et al. (2016). Purification and characterization of progenitor and mature human astrocytes reveals transcriptional and functional differences with mouse. Neuron 89, 37-53. doi: 10.1016/j.neuron.2015.11.013

Conflict of Interest: The authors declare that the research was conducted in the absence of any commercial or financial relationships that could be construed as a potential conflict of interest.

Publisher's Note: All claims expressed in this article are solely those of the authors and do not necessarily represent those of their affiliated organizations, or those of the publisher, the editors and the reviewers. Any product that may be evaluated in this article, or claim that may be made by its manufacturer, is not guaranteed or endorsed by the publisher.

Copyright (C) 2021 Horvat, Zorec and Vardjan. This is an open-access article distributed under the terms of the Creative Commons Attribution License (CC BY). The use, distribution or reproduction in other forums is permitted, provided the original author(s) and the copyright owner(s) are credited and that the original publication in this journal is cited, in accordance with accepted academic practice. No use, distribution or reproduction is permitted which does not comply with these terms. 